\title{
ADVANCED CONTROL SYSTEM FOR GRID-CONNECTED SOFC HYBRID PLANTS: EXPERIMENTAL VERIFICATION IN CYBER-PHYSICAL MODE
}

\author{
Mario L. Ferrari \\ mario.ferrari@unige.it \\ Alessandro Sorce \\ alessandro.sorce@unige.it
}

\author{
lacopo Rossi \\ iacopo.rossi@edu.unige.it
}

Aristide F. Massardo

massardo@unige.it

University of Genoa - Thermochemical Power Group (TPG), Genova, Italy

\begin{abstract}
This paper presents a Model Predictive Controller (MPC) operating an SOFC Gas Turbine hybrid plant at end-of-life performance condition. Its performance was assessed with experimental tests showing a comparison with a Proportional Integral Derivative (PID) control system. The hybrid system operates in grid-connected mode, i.e. at variable speed condition of the turbine. The control system faces a multivariable constrained problem, as it must operate the plant into safety conditions while pursuing its objectives. The goal is to test whether a linearized controller design for normal operating condition is able to govern a system which is affected by strong performance degradation. The control performance was demonstrated in a cyber-physical emulator test rig designed for experimental analyses on such hybrid systems. This laboratory facility is based on the coupling of a $100 \mathrm{~kW}$ recuperated microturbine with a fuel cell emulation system based on vessels for both anodic and cathodic sides. The components not physically present in the rig were studied with a real-time model running in parallel with the plant. Model output values were used as set-point data for obtaining in the rig (in real-time mode) the effect of the fuel cell system.

The result comparison of the MPC tool against a PID control system was carried out considering several plant properties and the related constraints. Both systems succeeded in managing the plant, still the MPC performed better in terms of smoothing temperature gradient and peaks.
\end{abstract}

\section{INTRODUCTION}

The forecasted growth in energy consumption coupled with the issue of $\mathrm{CO}_{2}$ emission containment highlighted significant limitations for current power plants [1]. For this reason, research and engineering activities are focused on the targets related to efficiency increase and the development of flexible low emission technologies [2]. Considering different solutions, ranging from the extensive application of renewable sources [3] to the optimized management of the existing systems [4], hybrid plants based on Solid Oxide Fuel Cell (SOFC) technology [5] are considered promising for future power generation. This is due to very high efficiency level of SOFC/mGT systems, obtainable even in small size units, coupled with low emission performance [6]. Moreover, these systems can operate with fuel flexibility performance ranging from natural gas to coal gasification products or biogas [7]. This aspect was specifically demonstrated considering different biogas compositions for the same hybrid plant [8]. The results presented in [8] showed the variation of fuel composition from $100 \% \mathrm{CH}_{4}$ to molar fractions of $50 \% \mathrm{CH}_{4}$ and $50 \% \mathrm{CO}_{2}$.

Although atmospheric SOFCs are able to reach interesting efficiency values in the $40 \%-50 \%$ range, the coupling with a gas turbine allows to obtain a further performance increase to values higher than $60 \%$ [9]. This is due to the benefit of SOFC pressurization coupled with the bottoming cycle energy harvesting. Moreover, the exhaust flow can be used for cogeneration [9].

In spite of the mentioned promising performance, SOFC-based hybrid systems are not ready for wide commercialization [10]. Just Mitsubishi Hitachi Power Systems declared in 2018 [11] to have received a first order for an SOFC/mGT system. High costs and not-demonstrated reliability [12] are important limitations, and some technical problems are not completely solved. Especially SOFC/GT integration [13] and the related 
control system issues [14] are still involving researchers and engineers due to system complexity, large amounts of constraints [15] and critical aspects related to component transient response. The main constraints to be considered are: SOFC and reformer maximum temperatures and temperature gradients, maximum acceptable anode-cathode differential pressure, Steam-to-Carbon ratio limits, maximum acceptable value for the turbine speed, surge limit for the compressor, turbine and recuperator temperature limits, and maximum operating performance of control valves. In details, an important aspect affecting the control system performance is the large difference between the response of the SOFC high thermal capacitance and the fast behavior of the turbine components. Although control strategies completely based on Proportional Integral Derivative (PID) tools have been proposed, further analysis demonstrated the benefits of advanced control approaches. In detail, considering the results obtained with PID tools, as [15] for an APU, [16] and [17] for a stationary system, researchers analyzed feed-forward solutions coupled with PIDs [18], fuzzy controllers [19], H-infinity based tools [20] and Model Predictive Control (MPC) based approaches. The work presented in [21] was a preliminary activity. Moreover, [22] used fuzzy Hammerstein models. MPC has a long history of successful application from component control to optimization of integrated systems [23] and it is possible to find different applications of the same architecture to solve different control problems. For instance, [24] built an MPC tool for an online system management, [25] studied a nonlinear MPC system for voltage control purpose, and [26] developed a Multi Input Multi Output (MIMO) MPC for closed-loop simulations in a tubular SOFC system. When compared to traditional PIDs, the MPC approach has largely demonstrated its better closed-loop performance and literature presents a large availability of applications of this control approach. Nevertheless, one of the main issue of model-based control process is the mismatch between process model and real plant. Indeed, the performance of the controller depends on the quality of the embedded model [27], considering special attention on the impact of disturbances and performance modifications.

In their lifetime, power plants evolve and different factors play a decisive role: degradation, component updating, modification to electronics, etc. As a consequence, it is important that the controller preserves its key strength over time and eventually secondary modifications to the original configuration, such as hardware or software changes in the power electronics. This is particularly important for a complex controller embedding a dynamic representation of the plant, because continuous updating would be hardly feasible in every day operating life - even though online system identification is coming up strongly [28] and different techniques have been applied to re-align transfer function based models to actual plant conditions $[29,30]$.

The capability of the controller to operate under lifetime dependent performance is particularly needed in the field of SOFC/GT hybrid plants since degradation is expected to play a key role in the management of the system itself and stack turnover [31]. This work aims, then, to demonstrate the robustness of a linearized MPC embedding a full physic model and designed to operate between $100 \%$ and $80 \%$ load, while the plant is operating below end-of-life conditions [32] and under some uncertainties. In the SOFC/GT hybrid system environment, a plant generating lower than $80 \%$ of the load is considered to be at end of its life from the stack side [32].

\section{NOMENCLATURE}

\begin{tabular}{|c|c|}
\hline Acronyms & \\
\hline$\overline{\mathrm{APU}}$ & Auxiliary Power Unit \\
\hline B & Blower \\
\hline $\mathrm{CV}$ & Check Valve \\
\hline DLR & German Aerospace Centre \\
\hline $\mathrm{FC}$ & Fuel Cell \\
\hline GT & Gas Turbine \\
\hline HS & Hybrid System \\
\hline HW & HardWare \\
\hline in & inlet \\
\hline M & Motor \\
\hline MIMO & Multi Input and Multi Output \\
\hline MPC & Model Predictive Control \\
\hline mGT & micro Gas Turbine \\
\hline NETL & National Energy Technology Laboratory \\
\hline OGB & Off-Gas Burner \\
\hline PE & Power Electronics \\
\hline PID & Proportional Integral Derivative controller \\
\hline PMC & Power Module Controller \\
\hline REC & Recuperator \\
\hline REF & Reformer \\
\hline SOFC & Solid Oxide Fuel Cell \\
\hline SW & SoftWare \\
\hline TPG & Thermochemical Power Group \\
\hline UDP & User Datagram Protocol \\
\hline VB & bleed valve \\
\hline $\mathrm{VC}$ & recuperator bypass valve \\
\hline VCC & fuel valves (pilot and main) \\
\hline VM & cathodic vessel bypass valve \\
\hline VP & ejector primary duct valve \\
\hline VO & cathodic vessel outlet valve \\
\hline VR & cathodic vessel inlet valve \\
\hline Variables & \\
\hline$\overline{\mathrm{A}, \mathrm{B}, \mathrm{C}}$ & matrixes for the MPC tool \\
\hline $\mathrm{FO}$ & Fractional Opening [\%] \\
\hline I & electrical current $[\mathrm{A}]$ \\
\hline $\mathrm{i}, \mathrm{j}$ & indexes \\
\hline $\mathrm{Kp}$ & surge margin $[-]$ \\
\hline LHV & Low Heating Value $[\mathrm{J} / \mathrm{kg}]$ \\
\hline $\mathrm{N}$ & rotational speed [rpm] \\
\hline $\mathrm{m}$ & mass flow rate $[\mathrm{kg} / \mathrm{s}]$ \\
\hline $\mathrm{P}$ & power $[\mathrm{W}]$ \\
\hline $\mathrm{S}(\mathrm{k})$ & cost function \\
\hline $\mathrm{Sec}$ & fuel cell active section $\left[\mathrm{m}^{2}\right]$ \\
\hline STCR & Steam-To-Carbon Ratio [-] \\
\hline $\mathrm{T}$ & temperature $[\mathrm{K}]$ \\
\hline
\end{tabular}




\begin{tabular}{ll}
$\mathrm{t}$ & time [s] \\
TIT & Turbine Inlet Temperature [K] \\
TOT & Turbine Outlet Temperature [K] \\
$\vec{u}$ & manipulated variable vector \\
$\vec{w}$ & vector of scalar values \\
$\vec{x}$ & vector of states \\
$\vec{y}$ & vector of controlled variables \\
$\beta$ & compression ratio [-] \\
Subscripts & \\
\hline $\mathrm{C}$ & Calculated \\
PID & Proportional \\
& controller \\
$\mathrm{f}$ & fuel \\
FC & Fuel Cell \\
HS & Hybrid System \\
IN & INlet \\
M & Measured \\
mGT & micro Gas Turbine \\
sl & surge limit \\
s.p. & set-point \\
&
\end{tabular}

\section{CYBER-PHYSICAL APPROACH}

The cyber-physical approach considered in this work integrates hardware with software in order to achieve a thorough investigation of expensive energy systems without losing hardware feedback. The SOFC stack, the most expensive component, is replaced with a real-time model coupled with the hardware to emulate this electrochemical reactor. The available rig of the University of Genoa is extensively described in $[33,34]$. This is not a unique example because several works were carried out on other similar test rigs. They are the plant available at the National Energy Technology Laboratory [35] and the test rig that operated at the German Aerospace Centre [36]) that demonstrated the effectiveness of the approach. Thanks to a cathodic vessel and an anodic side including an ejector and a further vessel, it was possible to emulate the system dynamic operations for performing tests on control systems. With this approach results were obtained during load changes for an MPC tool and a PID based controller. So, the paper focuses special attention on the comparison of the control performance obtained with these tools.

The experimental analysis on SOFC hybrid systems is carried out considering a rig designed for the emulation of these

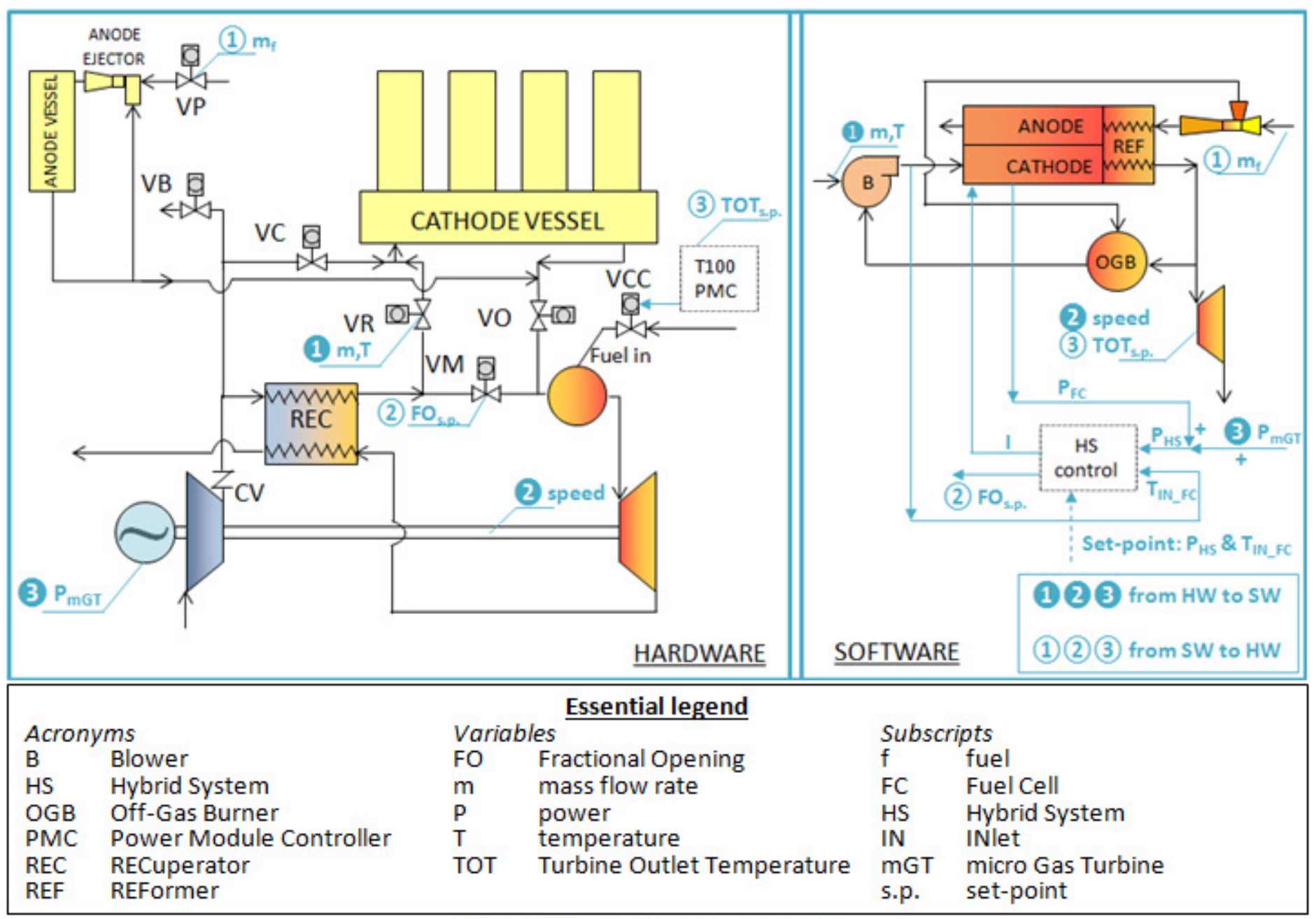

Figure 1. Cyber-physical approach. 
kinds of plants and operating in cyber-physical mode. As shown in Fig.1, this approach is based on the real-time communication between a real plant and a real-time model. They are respectively named "Hardware" and "Software" in Fig.1. It is necessary to generate, in the test rig, the same behavior of the coupling with an SOFC system. This communication is based on the User Datagram Protocol (UDP) approach. It operates with the data transfer shown in Fig.1 by the slanting broken lines. So, mass flow rate and temperature at the vessel inlet and T100 rotational speed are the data transferred from the plant to the model. On the other hand, calculated Turbine Outlet Temperature (TOT), fuel mass flow rate and VM fractional opening (FO) are the data transferred from the model to the plant.

The turbine and the anodic ejector are included in both hardware and software for plant/model coupling reasons: the turbine model is essential to calculate the TOT value $\left(\mathrm{TOT}_{\mathrm{C}}\right.$ ) that is used as set-point for the T100, and the ejector model is necessary for the anodic side property calculation. So, the TOT matching is carried out to couple the plant with the software for the temperatures and the mass flow rate matching in the ejector primary duct is necessary for the fuel flow emulation. While the model considers the real fuel, in the test rig this flow is emulated with the same amount of air mass flow rate. The same approach was used in [21] - which is the reference work on the development of the adopted MPC and validation in normal operating conditions. As previously mentioned, this work investigates a degraded system. Still, with respect to a previous work [21], the power plant underwent some maintenance operations which include in the end some uncertainties under the modeling viewpoint with a possible significant impact on the control system. These modifications regard new electronics for the microturbine power conditioning and the related upgrade on the software which has been completely revised and ported to 64 bit system. With this new hardware and software the T100 is operated with a variable speed control approach.

\section{The Plant}

The plant is composed of a T100 microturbine and an SOFC emulation system [37]. Although the turbine was modified for the connections to the additional components, its standard control logics were maintained in the rig. They are implemented in the Power Module Controller (PMC) that equips the commercial T100 units. The only difference from the commercial unit is the access to the TOT set-point, which can be changed in the 690-918.15 $\mathrm{K}$ range in agreement with the calculations, instead of the fixed $918.15 \mathrm{~K}$ value. So, the tests presented in this paper are based on the commercial PMC unit of the T100 machine including the control systems necessary to maintain the TOT at its set-point value and to match the generated electrical power with its demand through the rotational speed variation. No additional details are known about these control logics because they are not accessible for the users. However, the obtained results demonstrated the opportunity for applications of commercial turbines in hybrid systems. The SOFC emulation system consists of a cathodic modular vessel of $3.2 \mathrm{~m}^{3}$ total size and an anodic circuit managed by an ejector and including a $0.8 \mathrm{~m}^{3}$ vessel. The plant was sized considering a similitude approach [37] with the stack manufactured by Rolls-Royce Fuel Cell Systems [38]. The details reported in [37] show the considered process to scale up the $270 \mathrm{~kW}$ plant by Rolls-Royce Fuel Cell Systems to a 450 $\mathrm{kW}$ hybrid system sized for the T100 microturbine. It was not a simple scaling-up process due to some significant differences in terms of pressurization and components. For instance, a hybrid system based on the T100 turbine includes a recuperator instead of a cathodic ejector. The final hybrid system layout is shown in Fig.1: it is a hybrid system with the SOFC pressurized by the T100 turbine and the cathodic flow pre-heated thanks to the recuperator and a blower for generating a recirculation. The offgas burner (OGB in Fig.1) is located immediately upstream of the blower to exploit the related thermal effect for air preheating. The anodic side of the plant is similar to the one included in the plant by Rolls-Royce Fuel Cell Systems: an ejector generates a recirculation mixing the fresh fuel with a steam rich flow. This approach is necessary to avoid carbon deposition and to obtain the required steam and thermal energy for the reforming reactions (REF in Fig.1). More details about the component coupling and performance are shown in [38]. The main design performance data of the emulated hybrid system are reported in Table 1 on the basis of [37].

Table 1. Main design performance data of the emulated hybrid system.

\begin{tabular}{|l|c|c|}
\hline \multicolumn{1}{|c|}{ Property } & Value & Measurement unit \\
\hline HS power & 450 & $\mathrm{~kW}$ \\
\hline HS efficiency & 59.0 & $\%$ \\
\hline FC power & 380 & $\mathrm{~kW}$ \\
\hline FC efficiency & 51.8 & $\%$ \\
\hline FC current density & 2940 & $\mathrm{~A} / \mathrm{m}^{2}$ \\
\hline Natural gas flow rate & 0.019 & $\mathrm{~kg} / \mathrm{s}$ \\
\hline Fuel utilization factor & 0.8 & - \\
\hline Natural gas temperature & 293 & $\mathrm{~K}$ \\
\hline Air flow rate & 0.8 & $\mathrm{~kg} / \mathrm{s}$ \\
\hline Compression ratio & 3.8 & - \\
\hline
\end{tabular}

Considering what was reported in [21,33,37], attention is focused on the following additional components that were used for the tests reported in the paper:

- a cathodic vessel bypass line managed by the VM valve;

- three heat exchangers, that are not represented in Fig.1, for simplicity, to control the compressor inlet temperature [37].

- additional instrumentation for measurement of mass flow rate, pressure and temperature in the plant lines.

All the additional probes, the measurements carried out by the T100 instrumentation and the valve control signals are managed in LabVIEW. The probe accuracy for the instrumentation used in this work is: $\pm 2.5 \mathrm{~K}$ for the thermocouples and $\pm 1 \%$ for the other pressure and mass flow sensors. 


\section{The Model}

The model was developed in Matlab-Simulink considering the real-time performance target. It includes (as shown in Fig.1) the components not physically installed in the rig. They are the SOFC, the reformer, the off-gas burner (OGB), the cathodic blower and other two devices for plant/model matching: the T100 expander and the anodic ejector. While the turbine model is necessary to evaluate the TOT value, the anodic ejector tool calculates the mass flow rate in the primary duct. The fuel feeding the primary duct of the anodic ejector is pure methane. 0-D approach and further simplifications [39] were applied to all the components. However, a physical approach was considered for all the components including the discrete integration of the following differential equations carried out considering global input/output balances: mass, momentum and energy. Due to the time scales of the phenomena, the energy equation has an extreme importance for the analysis shown in this paper. It includes the thermal capacitance of components, especially for the SOFC and the reformer.

Considering that this model was presented in previous works (such as $[21,33,34]$ ), this paper summarizes the main component details:

- The SOFC is modeled subtracting the losses from the ideal voltage. Reactions are considered at equilibrium, CO electrochemical reaction is neglected, and the stack calculated on the basis of external adiabatic conditions.

- The reformer includes methane reforming and shifting reactions. It is based on an active surface for the heat transfer and catalytic reactions are at chemical equilibrium.

- The OGB includes the global energy balance related to the combustion of the fuel not reacting in the stack.

- The ejector tool is based on the mentioned fluid dynamic equations globally calculated on the components.

- The blower is modeled to evaluate the consumed power necessary to obtain the recirculation performance.

As presented in this assumption list, some important simplifications have been considered, such as the external adiabatic conditions considered for the SOFC model. They are linked with the simplifications necessary to obtain real-time performance. For instance, for the mentioned adiabatic conditions, a detailed thermal loss model is not able to improve the performance of SOFC outlet temperature calculation if the cell model is based on a 0-D approach, neglecting the real temperature inlet-outlet increase. However, as demonstrated in previous works $[18,21,33,34]$, this approach allows to evaluate significant results in terms of dynamic response and control system performance, that are the targets of this activity.

The model has been validated in several previous activities at both component (e.g. [40] for the ejector tool) and system level $[39,41]$.

\section{CONTROL SYSTEM FOR THE HYBRID PLANT}

The control system developed for the entire hybrid plant is included in the software box in Fig. 1 and named "HS control". It receives (as inputs) the set-point values and the measurements for the total produced net power and the cathode inlet temperature. As outputs, it calculates the fuel cell current value and the VM FO. The fuel mass flow rate is obtained through a look-up table as a function of the current to maintain the fuel utilization factor at 0.8 . Moreover the VM valve is used to control the bypass line: the SOFC air mass flow rate is changed to control the stack temperature. In the "HS control" box different control approaches can be considered. Since the aim of this work is the evaluation of the performance of an MPC tool, a result comparison was carried out. In details, the MPC tool performance was assessed against a PID-based controller. The results obtained with the PID tool can be considered as a base case obtained with the most common control technology. No feed-forward components were included to compare the extreme control solutions in terms of complexity. Both PID and MPC govern the system by acting on current and VM fractional opening (i.e. vessel bypass in Figure 1) in order to maintain constant cathode inlet temperature while tracking the load request.

\section{PID Control Approach}

This approach is based on two different closed loops, including the feedback, for both power and temperature control. As shown in Fig.2, the power difference between the HS setpoint and the T100 is the fuel cell power set-point value. It is necessary to evaluate the fuel cell current through a PID tool in a control loop including the fuel cell power feedback. Moreover, the error between the measured and the set-point values at the stack cathodic inlet is used to evaluate the VM fractional opening through a PID tool. No measurement system models were included because (in both cases) their response delay is negligible in comparison with the dynamic performance of the plant and the model components.
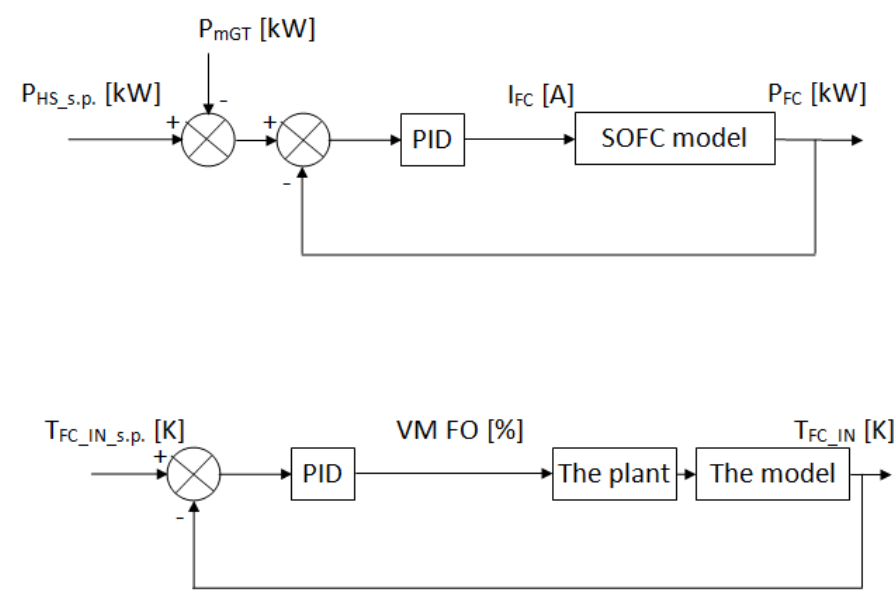

Figure 2. PID-based controllers.

The coefficients of these PIDs were defined considering the Ziegler-Nichols approach [42] and further optimized with preliminary tests. The coefficients were obtained for the specific test of this paper. 


\section{MPC Control Approach}

The MPC implemented architecture is the same adopted in previous works of the research group [21], that is, the Matlab MPC Toolbox by Mathworks [43]. It is a multi-input multioutput system operating on two properties: $\mathrm{P}_{\mathrm{HS}}$ and $\mathrm{T}_{\mathrm{FC} \text { IN }}$. Generally speaking, the MPC is a model based controller which makes use of a dynamic model of the target plant to estimate future operative points over a certain prediction horizon. Through the minimization of a cost function over this prediction, the controller implements the best solution for the next control action. This process occurs at each time step. The Matlab MPC is based on a quadratic cost function (Eq.1) composed by three different quadratic terms, each of them representing a different component (Eqs.2-4).

$$
\begin{gathered}
S(k)=S_{y}(k)+S_{\Delta u}(k)+S_{u}(k) \\
S_{y}(k)=\sum_{i=1}^{P} \sum_{j=1}^{n_{y}}\left\{w_{j}^{y}\left[r_{j}(k+i)-y_{j}(k+i)\right]\right\}^{2} \\
S_{\Delta u}(k)=\sum_{i=1}^{M} \sum_{j=1}^{n_{u}}\left\{w_{j}^{\Delta u} \Delta u_{j}(k+i-1)\right\}^{2} \\
S_{u}(k)=\sum_{i=1}^{M} \sum_{j=1}^{n_{u}}\left\{w_{j}^{u}\left[\bar{u}_{J}-u_{j}(k+i-1)\right]\right\}^{2}
\end{gathered}
$$

Considering the single terms of Eq.1, $S_{y}$ penalizes error on the output against the set-point, $S_{\Delta u}$ penalizes rapid changes in control variables, while $S_{u}$ penalizes the amplitude of control signal with respect to imposed nominal value. The importance of these components on the control action can be regulated through the scalar values $w_{j}$, which are basically weights that tune the response of the controller.

The adopted MPC uses a linear model for predictions, in the form of steady-state representation (Eq.5).

$$
\begin{gathered}
\vec{x}(k+1)=\boldsymbol{A} \vec{x}(k)+\boldsymbol{B} \vec{u}(k) \\
\vec{y}(k)=\boldsymbol{C} \vec{x}(k)
\end{gathered}
$$

However, the controlled plant has strong non-linearities, which means, a linearization is required. This process aims to create a model describing the target plant around certain operative conditions. In this case, the linearization process started from a detailed model of the plant. The linearization was carried out around three different operative points - in this case the work was done for $100 \%, 90 \%, 80 \%$ power [21]. The linearization process took into account most of the physics of the problem and in the end the embedded models are represented by 200 states each. It is therefore important to underline that the embedded model is not based on transfer function identification, but on linearization on a physics-based detailed model of the power plant.

\section{EXPERIMENTAL TESTS AND RESULTS}

\section{Test Setup}

To evaluate controller robustness and flexibility, the experimental tests were carried out with the T100 microturbine including an air leakage of about $20 \%$. This operating condition was obtained by loosening the bolts of the connection flanges at the entrance of the T100 case, between the cathodic vessel outlet and the combustor inlet. This was considered as representative of a strong degradation in the hybrid system. The tests were carried out with a good reproducibility performance due to the fact that previous long operations stabilized the leakage. Although it is not possible to have a direct measurement on the leakage mass flow rate, the comparison between different tests showed differences in the measured properties lower than $0.5 \%$. A hardware modification on the system was considered to be more stressful for the controller rather than creating some discrepancies on the model. Moreover, since (in comparison with [21]) the T100 power electronics and control system were updated, an additional constraint was included. It is a threshold in the T100 power conditioning components related to a voltage maximum acceptable value for the direct current bar. It was not present in the components used in [21]. This is an important additional aspect in the optic of MPC tool performance assessment. So, for this reason, the mass flow rate measured at the cathodic vessel inlet (used as input for the model) decreased by about $33 \%$ generating a significant decay in the hybrid system power. The degraded condition for the hybrid plant was not based on a coefficient, but it was calculated with the model from the reduced available air mass flow rate at the SOFC inlet and considering the same cathode inlet temperature of the system working in full-load on-design conditions.

After the T100 start-up, the SOFC emulator connection, and the reaching of steady-state conditions it was possible to perform the tests in cyber-physical mode. The compressor inlet temperature was maintained at $300 \mathrm{~K}( \pm 0.5 \mathrm{~K})$ during the entire tests.

The impact of the probe accuracy on the calculated values reported here generated the following error ranges: $\pm 1 \%$ for the global HS power, $\pm 0.7 \%$ for the $\mathrm{TOT}_{\mathrm{C}}, \pm 2 \%$ for the surge margin, $\pm 0.2 \%$ for the SOFC voltage and $\pm 1.1 \%$ for the STCR.

\section{Test Results}

The power target trend for the entire hybrid system is shown in Fig.3. After $100 \mathrm{~s}$ at $278 \mathrm{~kW}$ condition, this set-point value was decreased to $222 \mathrm{~kW}$ with a $900 \mathrm{~s}$ ramp, that is about a $3.7 \mathrm{~kW} / \mathrm{min}$ decrease. Then, this target was constant for 1,000 $\mathrm{s}$ before an increase ramp up to $278 \mathrm{~kW}$ again. Also this power set-point change was operated in $900 \mathrm{~s}$. Finally, the $278 \mathrm{~kW}$ condition was kept up to the end of these hour-long tests. The $278 \mathrm{~kW}$ condition is significantly lower than the design value due to the mentioned air leakage representative of the degraded hybrid system. The results presented in Fig. 3 and in this entire section show the comparison between two tests run with the same operative conditions, but managed by the two different 
control systems (with the PID or the MPC technology). As an initial result, Fig. 3 also shows the generated total hybrid system power: for both control approaches the obtained values are in good agreement with the target.

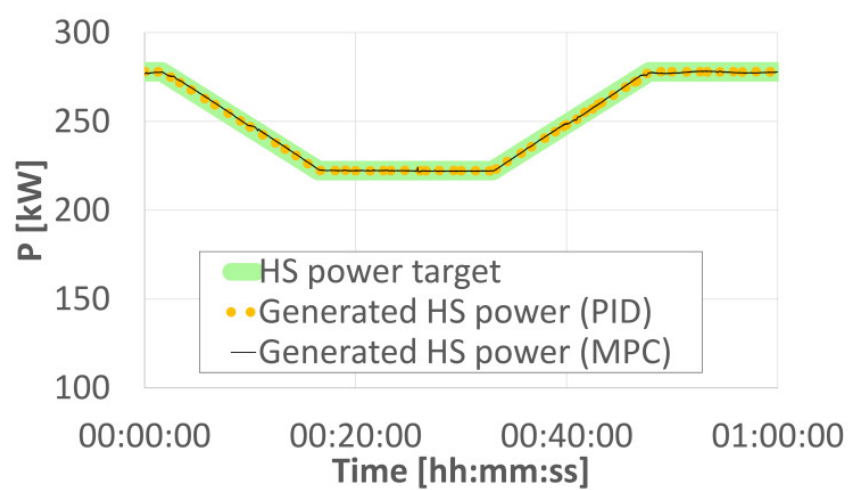

Figure 3. Hybrid system power: target and generated values for both PID and MPC control tools.

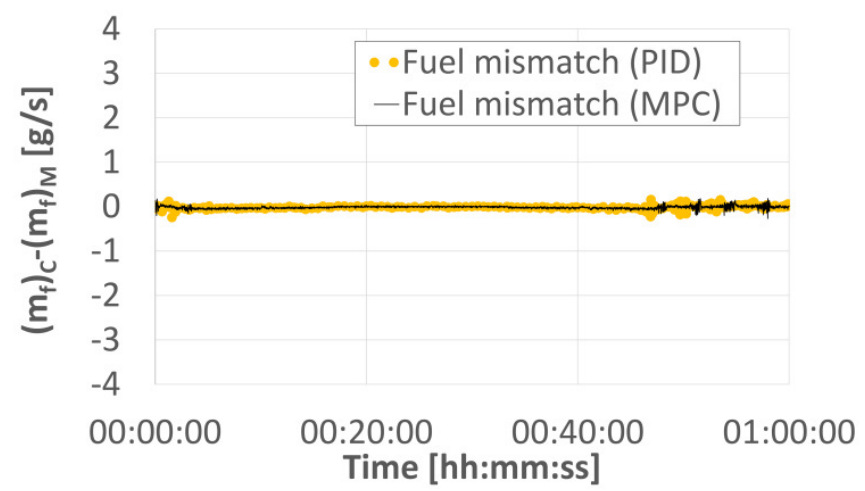

Figure 4. Mismatch between calculated and measured values for the fuel mass flow rate for both PID and MPC control tools.

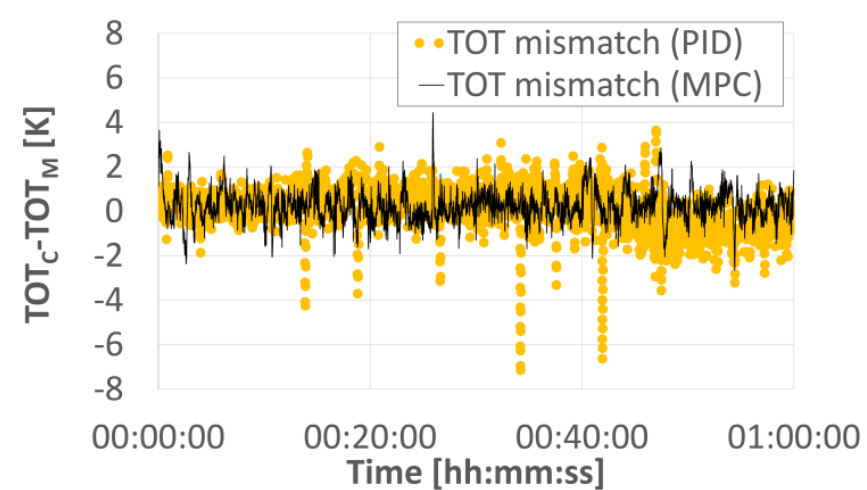

Figure 5. Mismatch between calculated and measured values for the TOT for both PID and MPC control tools.

Since the response of the VP valve is lower than $0.5 \mathrm{~s}$, the matching between the set-point by the model and the real mass flow rate values in the ejector primary duct is good (Fig.4). The matching between the calculated TOT and the obtained related values in the test rig is shown in Fig.5. Although the mismatch is mainly contained in the $\pm 2 \mathrm{~K}$ band, some peaks are present especially for the PID controller. Since these peaks have a duration lower than 2-4 s, the average trend of the measured TOT well matches its set-point calculated by the model. So, the plant correctly represents the behavior of a T100 microturbine connected with an SOFC system and this result demonstrated the reliability of this cyber-physical approach.

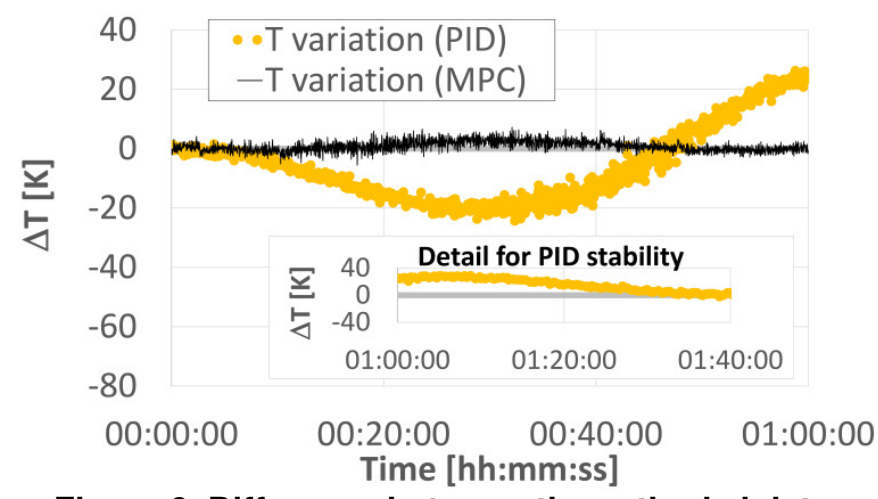

Figure 6. Difference between the cathode inlet temperature and its set-point: comparison between PID and MPC control tools.

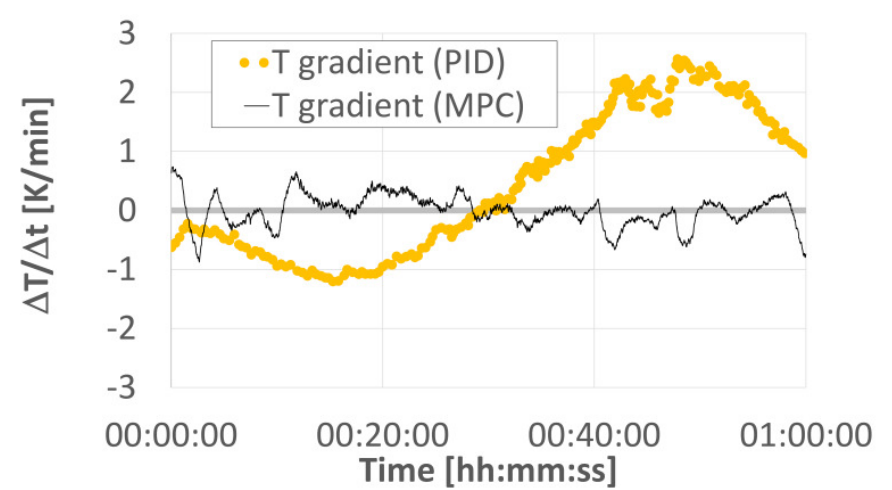

Figure 7. Temperature gradient at the cathode inlet: comparison between PID and MPC control tools.

Figure 6 and 7 are the most important plots to demonstrate the robustness and the performance of the MPC tool against the PID-based control approach. The stability of the PID tool was verified and reported in the detail of Fig.6: maintaining the power constant after the $1 \mathrm{~h}$ test, the cathode inlet temperature of the PID case reached the set-point in about 40 minutes. The cathode inlet temperature is controlled operating on the VM valve that is able to bypass a fraction of the air flow rate. A significant improvement was obtained with the MPC tool because it was able to contain the cathode inlet temperature oscillations in a $\pm 5 \mathrm{~K}$ range, while the PID-based controller exceeded the $\pm 25 \mathrm{~K}$ band. Although in comparison with [21] the oscillation range increased (from $\pm 2 \mathrm{~K}$ to $\pm 5 \mathrm{~K}$ ) for the MPC case, it is a good performance considering the degraded conditions of the system. So, thanks to the predictive part, it is possible to solve the control issues related to the SOFC 
temperature. This is an important critical aspect due to the large difference between the high thermal capacitance of the SOFC and the low mechanical inertia of the machine shaft. On the other hand, the control approach based on PID tools is not able to prevent large temperature oscillations that lead to SOFC significant damage due to excessive temperatures.

This discussion is completed by the time-dependent temperature gradient reported in Fig. 7 for both PID and MPC controllers. Also this property shows the better performance obtained with the MPC tool because it produced a gradient inside the $\pm 1 \mathrm{~K} / \mathrm{min}$ band. On the other hand, the PID-based control system generated gradient values reaching $2.7 \mathrm{~K} / \mathrm{min}$. Performance of the PID is anyway acceptable for SOFC stack preserving, still the gap with the MPC performance is significant. For these reasons, faster or larger load variations could be critical for the thermal stress on the stack components.

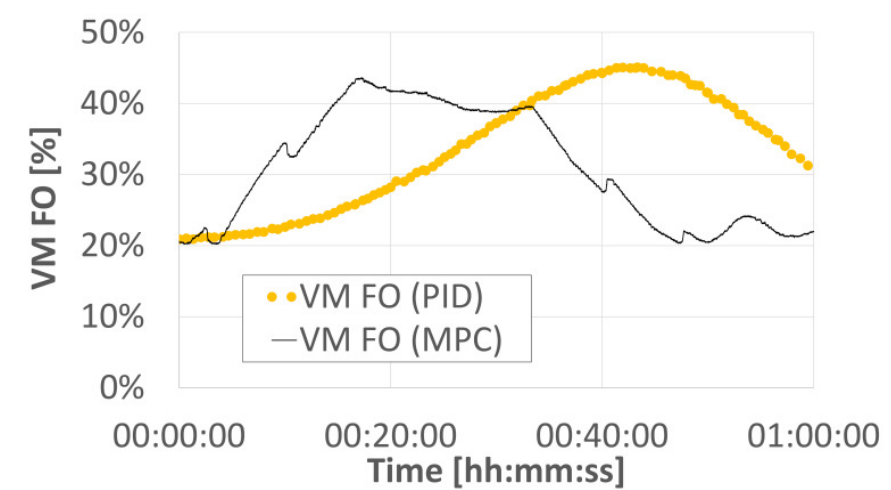

Figure 8. VM valve fractional opening: comparison between PID and MPC control tools.

Figure 8 shows the fractional opening (FO) value of VM valve used for system control, for both PID and MPC. The control action on the VM can be explained by considering the need to compensate power (and fuel cell current) decrease. In this case, the SOFC air flow rate has to be decreased as well. This is carried out by opening the VM valve that directly diverts the flow to the T100 combustor inlet, bypassing the SOFC vessel. So, in both PID and MPC cases the FO value increased due to the effect of power decrease. Though the difference in behavior is evident, the MPC performs a faster still stable response if compared to the PID. This behavior was able to avoid large temperature oscillations, as discussed previously. The slight discontinuities in the FO trend for the MPC case correspond to model switching while operating, as presented in [21]. Multiple MPC was used because this control tool was set considering a linearized system, while the controlled plant is not linear. So, a linearization in different operational points was considered [21]. Due to the large SOFC thermal capacitance, additional oscillations in the temperatures were not generated. Another direct effect of the VM trend is the mass flow rate at the cathode inlet (Fig.9). The values reported in Fig.9 are the mass flow rates calculated by the model for the duct connecting the blower to the SOFC cathode side. Also in this case some discontinuities are visible for the MPC case, while the PID tool produced an oscillation with the same response performance shown in Fig.8.

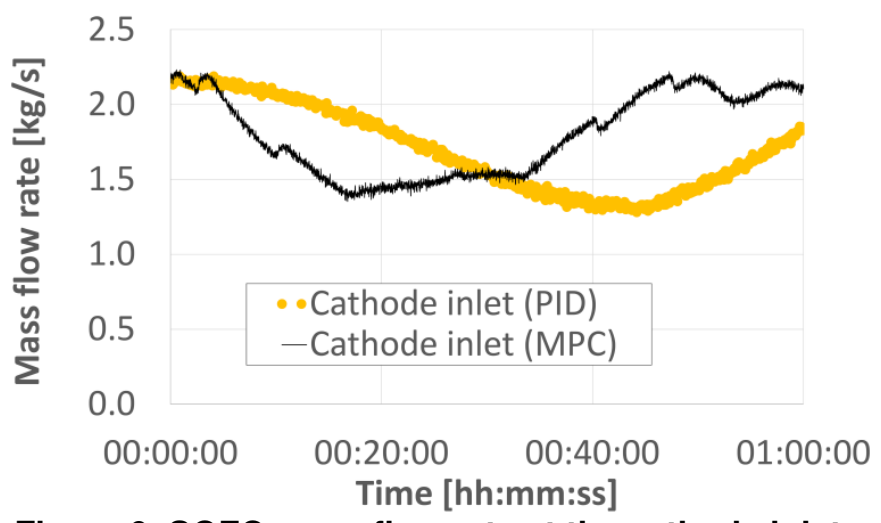

Figure 9. SOFC mass flow rate at the cathode inlet: comparison between PID and MPC control tools.

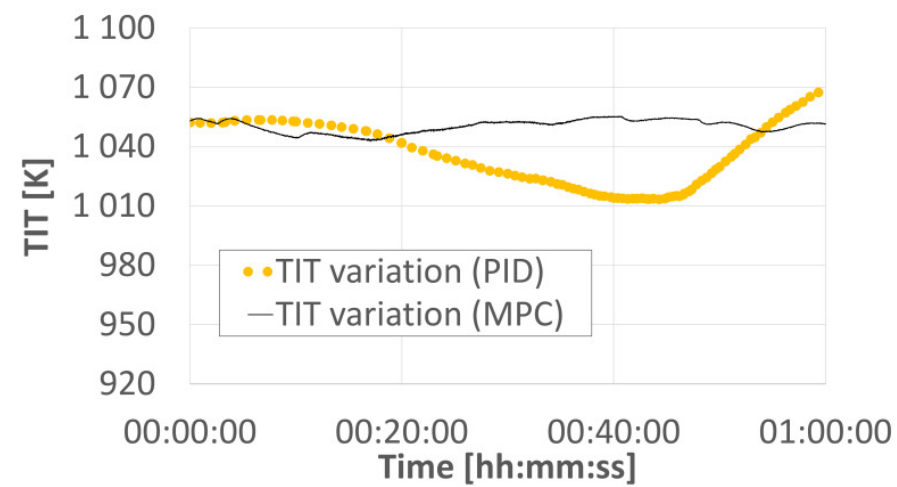

Figure 10. TIT: comparison between PID and MPC control tools.

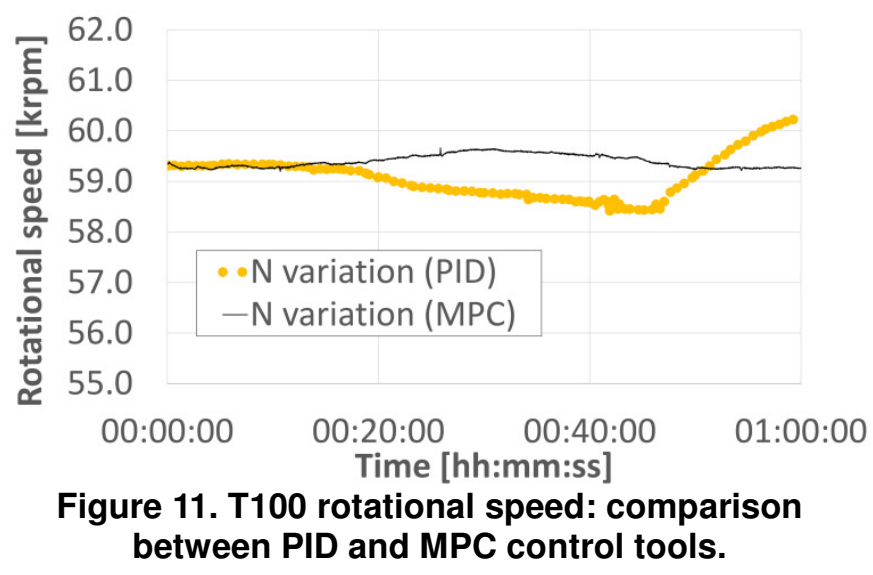

The presentation of the T100 behavior is completed reporting the trends of the Turbine Inlet Temperature (TIT) and the rotational speed (Figs.10 and 11). For both properties, the influence of cathode inlet temperature trend is well visible: a significant oscillation for the PID tool versus almost constant trend for the MPC controller. Moreover, Fig. 12 shows the surge margin of the T100 compressor (defined as in Eq.6), calculated 
with a post processing activity. Since the compressor model is not included in the real-time tool, it is necessary to calculate the surge margin after the tests. Due to the air leakage and the VM opening the surge margin is very high without any stability risks. The trend is almost constant in both cases due to the combined effects of the variation of VM fractional opening and the rotational speed change.

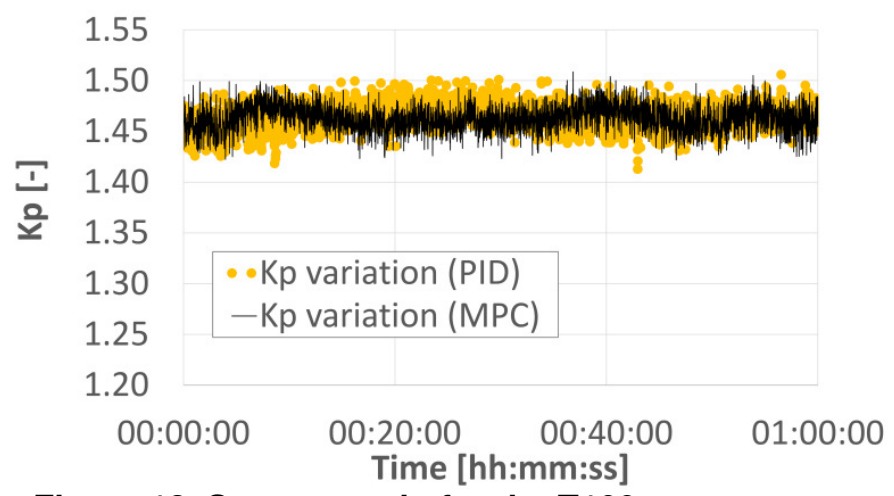

Figure 12. Surge margin for the T100 compressor: comparison between PID and MPC control tools.

$$
K p=\frac{\beta_{s l} \cdot m}{\beta \cdot m_{s l}}
$$

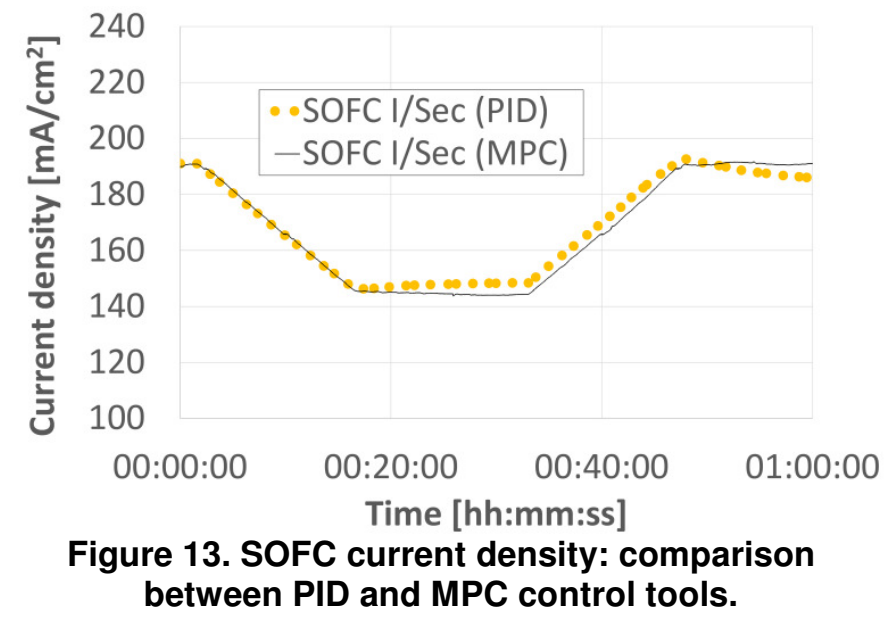

Focusing special attention on the SOFC main properties, Figs.13 and 14 show the current density and the real voltage of the stack. The current density trends are very similar to the demand trend for both PID and MPC cases. Slight property variations are present for the PID case in the constant power demand zone. This is due to the mGT behavior generated by the VM FO trend and the related effect on the SOFC temperature. The voltage plot (Fig.15) shows an important influence of the current density trend: the current decrease generated a decay in the electrical losses and a consequent voltage increase.

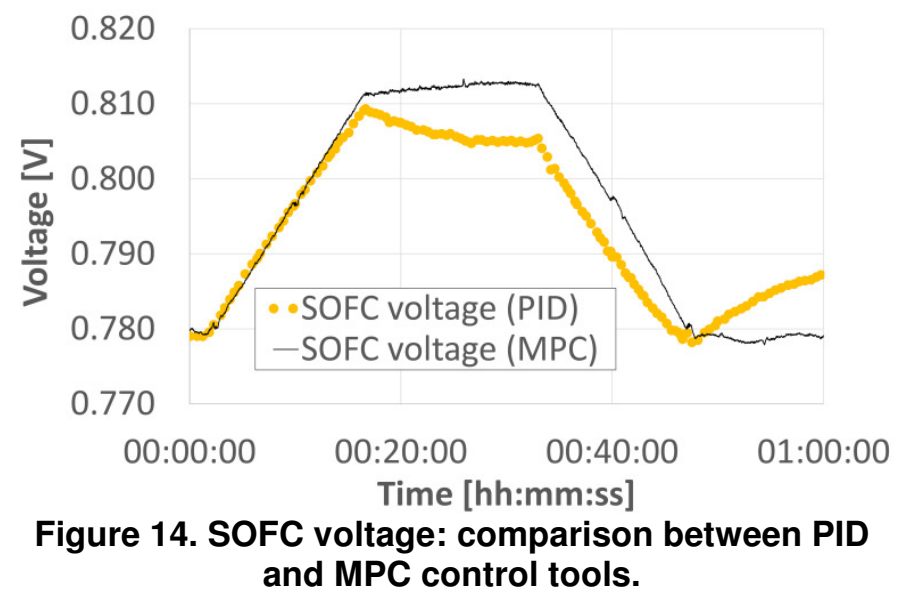

The stability of the controller is essential not only to properly govern the cathode inlet temperature, but also to preserve other key parameters from severe transitions. An example is given by the Steam-to-Carbon ratio (STCR), defined as in Eq.7 and reported in Fig.15. This is computed in real-time mode through the plugged model. Both cases operate at a high STCR with a significant margin from the 1.8 limit [44], but the MPC tool is able to produce a more stable behavior: $\pm 1 \%$ for the MPC against $\pm 3 \%$ for the PID. The oscillation for the PIDbased control system, even though not critical for this case, could generate some carbon deposition risks in other transient operations.

$$
\operatorname{STCR}=\frac{n\left(\mathrm{H}_{2} \mathrm{O}\right)}{n(\mathrm{CO})+\mathrm{n}\left(\mathrm{CH}_{4}\right)}
$$

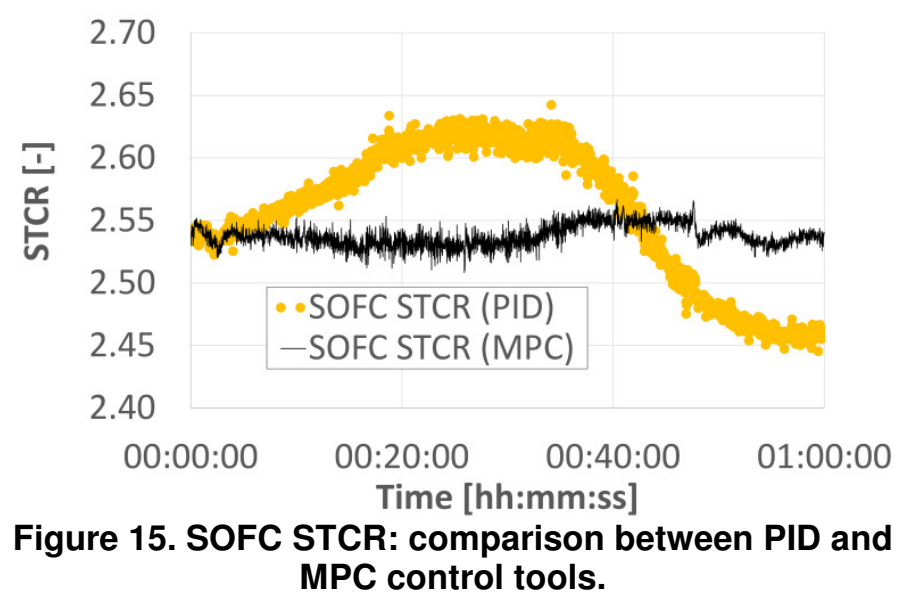

\section{CONCLUSIONS}

This paper presents experimental tests on hybrid system controllers carried out with the emulator rig by the TPG operating in cyber-physical mode. In details, the performance obtained using the MPC architecture is compared with the plant behavior with the PID-based approach. The MPC embeds a highly detailed model of the target plant, consisting on a linearized approach of a physical model which gave three 
different state space representations of the system defined by 200 states each. These tests were performed considering these conditions: (i) new electronics and new software for the microturbine power conditioning and control (in comparison with [21]), (ii) variable speed control approach, (iii) complete management of the entire hybrid system power, (iv) microturbine including an air leakage to represent a degraded system, (v) same controllers of [21] for both PID and MPC tools. The main results obtained with this work are summarized in the following points.

- Both controllers are stable also under these operative conditions: new electronics and software for the microturbine, complete management of the system power and degraded microturbine. This demonstrated good robustness and flexibility.

- The obtained results in terms of cathode inlet temperature show a better behavior with the MPC tool against the PIDbased controller. In details, oscillations are in the $\pm 5 \mathrm{~K}$ range for the MPC, against the $\pm 25 \mathrm{~K}$ range for the PID. So, the MPC was able to prevent large temperature oscillations that lead to SOFC significant damage due to excessive temperatures or forces to fix large temperature margins from the maximum acceptable values, decreasing the system efficiency.

- Also the obtained results in terms of time-dependent gradient for the cathode inlet temperature shows a better behavior with the MPC against the PID: the maximum gradient values are in the $\pm 1 \mathrm{~K} / \mathrm{min}$ range for the MPC, against peaks close to the $\pm 3 \mathrm{~K}$ values for the PID. So, also for this parameter the MPC tool was demonstrated more effective for the SOFC thermal stress limitation.

- Similar performance aspects can be discussed for the other plant properties: the MPC tool operated with reduced oscillation size. For instance, the STCR presents the following oscillation size: $\pm 1 \%$ for the MPC against $\pm 3 \%$ for the PID. Therefore, the oscillation for the PID-based control system, even though not critical for this case, could generate values lower than 1.8 with carbon deposition risks for larger power variations or other transient operations.

The obtained results are significant since the MPC integrating a physics based linearized model was able to operate an end-of-life SOFC/GT hybrid system properly. So, the MPC tool, although more complex than the PID-based one, presents better performance in terms of oscillation smoothing with a significant advantage for the stress decrease on the SOFC. Moreover, the operations under the degraded conditions considered here showed a good flexibility and robustness of this tool. For this reasons, the MPC is also the best candidate to manage larger load variations. Although this approach was demonstrated an effective complexity/performance balance for this plant, non-linear MPC tools will be considered for different kinds of hybrid systems currently under investigation at TPG. Moreover, the TPG is working on further analyses on the impact of SOFC degradation or fuel change. Further tests can be accomplished by considering a different MPC integrating a different approach model - with a reduction states order. In this way a benchmark based on different modelling approaches can validate the obtained results and verify whether the detail of the embedded model gives a contribution in robustness of control action.

\section{ACKNOWLEDGMENTS}

The authors hereby devote an acknowledgement to Dr. Matteo Pascenti, laboratory technician at TPG, and Mr. Luca Mantelli, Ph.D. student at TPG, for their efforts in the tests and result analyses.

This plant was partially funded by: (i) FP6 and FP7 EU projects, (ii) National projects, and (iii) Rolls-Royce Fuel Cell Systems company.

\section{REFERENCES}

[1] U.S. Energy Information Agency, 2013, "International Energy Outlook 2013”, U.S. Department of Energy, Washington, DC.

[2] Rossi I., Sorce A., Traverso A., Gas turbine combined cycle start-up and stress evaluation: A simplified dynamic approach. Applied Energy, 190 (2017) 880-890.

[3] Demirbas A., Potential applications of renewable energy sources, biomass combustion problems in boiler power systems and combustion related environmental issues. Progress in Energy and Combustion Science, 31 (2005) 171-192.

[4] Yan J., Chou S.K., Desideri U., Xia X., Innovative and sustainable solutions of clean energy technologies and policies (Part I). Applied Energy, 130 (2014) 447-449.

[5] Saebea D., Magistri L., Massardo A., Arpornwichanop A., Cycle analysis of solid oxide fuel cell-gas turbine hybrid systems integrated ethanol steam reformer: Energy management. Energy, 127 (2017) 743-755.

[6] Lundberg W.L., Veyo S.E., Moeckel M.D., A HighEfficiency Solid Oxide Fuel Cell Hybrid Power System Using the Mercury 50 Advanced Turbine Systems Gas Turbine, Journal of Engineering for Gas Turbines and Power, 125 (2003) 51-58.

[7] Marsano F., Magistri L., Bozzolo M., Tarnowski O., Influence of Fuel Composition on Solid Oxide Fuel Cell Hybrid System Layout and Performance, ASME Paper GT2004-53853, ASME Turbo Expo, Vienna, Austria, 2004.

[8] Mantelli L., De Campo M., Ferrari M.L., Magistri L., Fuel flexibility for a turbocharged SOFC system. $10^{\text {th }}$ International Conference on Applied Energy (ICAE2018), Hong Kong, China, 2018.

[9] Larminie J, Dicks A., Fuel Cell Systems Explained, Second Edition, Wiley, 2003.

[10] Zaccaria V., Tucker D., Traverso A., Cold-Air Bypass Characterization for Thermal Management of Fuel Cell Gas Turbine Hybrids. Journal of Engineering for Gas Turbines and Power, 139 (2017) 062701_1-8.

[11] MHPS wins first order for integrated SOFC/gas turbine hybrid unit. Fuel Cells Bulletin, (2018) 6. 
[12] Zaccaria V., Tucker D., Traverso A. A distributed realtime model of degradation in a solid oxide fuel cell, part I: Model characterization. Journal of Power Sources, 311 (2016) 175181.

[13] Yi J.H., Kim T.S., Effects of fuel utilization on performance of $\mathrm{SOFC/gas}$ turbine combined power generation systems, Journal of Mechanical Science and Technology, 31 (2017) 3091-3100.

[14] Szabłowski Ł., Milewski J., Badyda K., Kupecki J., ANN-supported control strategy for a solid oxide fuel cell working on demand for a public utility building. International Journal of Hydrogen Energy, 43 (2018). $3555-3565$.

[15] Jia Z., Sun J., Oh S.-R., Dobbs H., King J., Control of the dual mode operation of generator/motor in SOFC/GT-based APU for extended dynamic capabilities. Journal of Power Sources, 235 (2013) 172-180.

[16] Stiller C., Thoruda B., Bolland O., Kandepu R., Lars Imsland L., Control strategy for a solid oxide fuel cell and gas turbine hybrid system. Journal of Power Sources, 158 (2006) 303-15.

[17] Wua X.-J., Zhub X-J., Multi-loop control strategy of a solid oxide fuel cell and micro gas turbine hybrid system. Journal of Power Sources, 196 (2011) 8444-8449.

[18] Caratozzolo F., Ferrari M.L., Traverso A., Massardo A.F., Experimental Test of Temperature and Power Control for a SOFC Hybrid System Emulator, ISABE-2013-1708.

[19] Shamoushaki M., Ehyaei M.A., Ghanatir F., Exergy, economic and environmental analysis and multi-objective optimization of a SOFC-GT power plant. Energy, 134 (2017) 515-531.

[20] Tsai A., Banta L., Tucker D., Gemmen R., Multivariable robust control of a simulated hybrid solid oxide fuel cell gas turbine plant. Journal of Fuel Cell Science and Technology, 7 (2010) 041008_1-9.

[21] Larosa L., Traverso A., Ferrari M.L., Zaccaria V., Pressurized SOFC Hybrid Systems: Control System Study and Experimental Verification. Journal of Engineering for Gas Turbines and Power, 137 (2015) 031602_1-8.

[22] Jurado F., Predictive Control of Solid Oxide Fuel Cell Using Fuzzy Hammerstein Models. Journal of Power Sources, 158 (2006) 245-253.

[23] D'Amato F., Industrial Application of Model Predictive Control Solution for Power Plant Startups. IEEE International Conference on Control Applications, Munich, Germany, 2006.

[24] Jurado F., Ortega M., Model Based Predictive Control of Fuel Cells. Electrical Power Components and Systems, 34 (2006) 587-602.

[25] Wu X. J., Zhu X. J., Cao G. Y., Tu H. Y., 2008, "Predictive Control of SOFC Based on a GA-RBF Neural Network Model. Journal of Power Sources, 179 (2008), 232-239.

[26] Spivey B. J., Edgar T. F., Dynamic Modeling, Simulation, and MIMO Predictive Control of a Tubular Solid Oxide
Fuel Cell. Journal of Process Control, 22 (2012) 15021520.

[27] Badwe A.S., Shah S.L., Patwardhan S.C., Patwardhan R.S., Model-Plant Mismatch Detection in MPC Applications using Partial Correlation Analysis. IFAC Proceedings Volumes, 41 (2008) 14926-14933.

[28] Tsai A., Pezzini P., Tucker D., Bryden K.M. MultipleModel Adaptive Control of a hybrid Solid Oxide Fuel Cell Gas Turbine power plant simulator. ASME Paper GT2017-64987, ASME Turbo Expo 2017, Charlotte, North Carolina (USA).

[29] Ling D., Zheng Y., Zhang H., Yang W., Tao B., Detection of model-plant mismatch in closed-loop control system. Journal of Process Control, 57 (2017) 66-79.

[30] Badwe A.S., Gudi R.D., Patwardhan R.S., Shah S.L., Patwardhan S.C., Detection of model-plant mismatch in MPC applications. Journal of Process Control, 19 (2009) 1305-1313.

[31] Rossi I., Zaccaria V., Traverso A., Advanced Control for Clusters of SOFC/Gas Turbine Hybrid Systems. Journal of Engineering for Gas Turbines and Power, 140 (2018) 051703_1-8.

[32] Zaccaria V., Tucker D., Traverso A., Operating strategies to minimize degradation in fuel cell gas turbine hybrids. Applied Energy, 192 (2017) 437-445.

[33] Caratozzolo F., Ferrari M.L., Traverso A., Massardo A.F., Real-time hardware-in-the-loop tool for a fuel cell hybrid system emulator test rig, ASME Paper FuelCell2011-54, 9th International Conference on Fuel Cell Science, Engineering and Technology, Washington, DC, USA, 2011.

[34] Caratozzolo F., Ferrari M.L., Traverso A., Massardo A.F., Emulator rig for SOFC hybrid systems: Temperature and power control with a real-time software. Fuel Cells, 13 (2013) 1123-1130.

[35] Tucker D., Liese E., Van Osdol J. G., Lawson L. O., Gemmen R. S., Fuel Cell Gas Turbine Hybrid Simulation Facility Design. ASME Paper No. IMECE2002-33207, 2003.

[36] Hohloch M., Huber A., Aigner M., Experimental investigation of a sofc/mgt hybrid power plant test rig impact and characterization of a fuel cell emulator, ASME Paper GT2016-57747, ASME Turbo Expo 2016, Seoul, South Korea.

[37] Ferrari M.L., Pascenti M., Magistri L., Massardo A.F., Hybrid System Emulator Enhancement: Anodic Circuit design, ICEPAG2009-1041, ICEPAG 2009, New Port Beach, California, USA.

[38] Agnew G.D., Bozzolo M., Moritz R.R., Berenyi S., The Design and Integration of the Rolls-Royce Fuel Cell Systems 1MW SOFC, ASME Paper GT2005-69122, ASME Turbo Expo 2005.

[39] Ghigliazza F., Traverso A., Massardo A.F., Wingate J., Ferrari M.L., Generic Real-Time Modeling of Solid Oxide Fuel Cell Hybrid Systems. Journal of Fuel Cell Science and Technology, 6 (2009) 021312_1-7. 
[40] Ferrari M.L., Pascenti M., Massardo A.F., Ejector Model for High Temperature Fuel Cell Hybrid Systems: Experimental Validation at Steady-State and Dynamic Conditions, Journal of Fuel Cell Science and Technology, 5 (2008) 041005, 1-7.

[41] Pezzini P., Caratozzolo F., Traverso A., Real-time simulation of an experimental rig with pressurized SOFC, ASME Paper GT2011-45527, ASME Turbo Expo, Vancouver, British Columbia, Canada, 2011.

[42] Skogestad S., Chemical and Energy Process Engineering, CR Press, 2008.
[43] Honc D.' Sharma R.K." Abraham A., Dušek F., Pappa N.Teaching and Practicing Model Predictive Control. IFAC-PapersOnLine, 49 (2016) 34-39.

[44] Marsano F., Magistri L., Massardo A.F., Ejector performance influence on a solid oxide fuel cell anodic recirculation system. Journal of Power Sources, 129 (2004) 216-228. 